\title{
Entre verdade e ilusão: corpo e mundo em Arthur Schopenhauer
}

\author{
Ana Carolina Soliva Soria
}

Pós-doutoranda em Filosofia pela USP

Resumo: 0 presente estudo pretende analisar, na obra de Schopenhauer, em que medida o próprio corpo do sujeito pode ser entendido como o ponto de contato entre os domínios físico e metafísico do mundo, e a importância das noções de verdade e ilusão para a construção das concepções de corpo e de mundo.

Palavras-chave: Corpo, Mundo, Verdade, llusão, Vontade
Abstract: The present study has the purpose of analyzing, in Schopenhauer's work, in which measure the own body can be understood as the contact point between the physical realms of the and metaphysical world, and the importance of the notions of truth and illusion to the building of the conceptions of body and world.

Key words: Body, World, Truth, Illusion, Will

Segundo Schopenhauer, o conhecimento do mundo se fundamenta sobre as diferentes classes do princípio de razão suficiente, a saber: a do devir, que rege as representações intuitivas dadas pelo entendimento; a do ser, dado pelas formas a priori do espaço e do tempo; a do conbecer, que dirige as representações abstratas dadas pela razão; e a do agir, que rege a motivação. O princípio de razão, tomado em seu conjunto, pode ser entendido como a condição de possibilidade de todo objeto. Contudo, tal princípio não se encontra nos próprios objetos, considerados independentes do sujeito. Eles são as condições de relação que o sujeito aplica aos objetos de sua representação em suas determinações recíprocas. Um objeto não pode ser representado independentemente de certas relações. Ele está, em primeiro lugar, em relação a um sujeito que, como tal, é a condição de toda representação. Além disso, os objetos estão em relação de determinação recíproca, que permite as suas mais diversas apresentações. Todas as alterações 
e mudanças que aparecem na representação devem ser previstas e regidas pelas classes do princípio de razão.

O devir é a modalidade que rege as representações dos objetos empíricos. Na apreensão destes, ele aparece como lei da causalidade, pela qual cada novo estado do objeto deve ser precedido de outro. A temporalidade não pode ser desconsiderada da sucessão que se estabelece entre o primeiro e o segundo estados, os quais Schopenhauer denomina causa e efeito (Ursacbe und Wirkung). A apreensão do mundo efetivo (wirklichen Welt), em seus elementos formal (espaço e tempo) e material (atividade), é feita mediante o conhecimento do efeito pela causa, e esta relação apenas pode ser estabelecida "pelo" (durcb) e "para" (für) o entendimento. No homem, os simples dados dos sentidos, subtraídos da lei da causalidade (Kausalität), são sensações vagas e confusas das modificações do objeto imediato (corpo). O fato, por exemplo, de recebermos dos olhos duas impressões visuais e unificarmos essas informações em uma representação única ou de reinvertermos a imagem dos objetos que é invertida no fundo do olho nos mostra que a intuição (Anschauung) "não é meramente sensual, mas intelectual, isto é, conhecimento puro do entendimento da causa pelo efeito; por conseguinte, supõe a lei da causalidade"1. A intuição é intelectual, pois, tal como escreve o filósofo, depende sempre da determinação da sequência causal que é dada pelo entendimento.

É pela lei da causalidade que se pode mostrar como a realidade empírica concorre para um sujeito que a concebe. A efetividade (Wirklicbkeit) que se atribui ao mundo exterior funda-se sobre o sujeito, e, com isso, todo o universo da representação é reduzido à condição de objeto para um sujeito. A lei da causalidade condiciona a intuição dos objetos; daí, temos que no âmbito da representação, o ser do objeto é o seu agir (Wirken) - que consiste em ser causa e efeito - e que nessa atividade encontra-se a sua efetividade. Procurar a existência dos objetos fora da representação do sujeito, ou em algo diferente de seu agir, escreve Schopenhauer, "não tem nenhum sentido e é uma contradição" (keinen Sinn bat und ein Widersprucb ist) ${ }^{2}$.

1. SCHOPENHAUER, A. Die Welt als Wille und Vorstellung. In: Sämtliche Werke. Vol. I. Ed. Wolfgang Frhr. von Löhneysen, Frankfurt am Main: Suhrkamp, 1986a, §4, p. 43

2. Idem, §5, p. 45 . 
Sendo assim, podemos nos perguntar se o agir (Wirken) que confere efetividade (Wirklicbkeit) ao mundo não seria, em primeiro lugar, a própria atividade sintética do entendimento, que une o espaço e o tempo - condições formais - na representação da matéria, dando sentido (Sinn) às representações. A essa atividade não poderíamos denominar também criação (schaffen) $)^{3}$ e entender todo o universo da intuição como uma produção do sujeito? Se a efetividade está na ação e toda representação se remete a um sujeito que conhece, como estar seguro de que o mundo não seja mera aparência destituída de um fundamento objetivo? Se o mundo depende da criação do sujeito, como garantir a distinção entre verdade e ilusão? Nas palavras de Schopenhauer:

Queremos saber a significação daquelas representações: perguntamos se esse mundo não é nada mais que representação, em qual caso teria de se apresentar a nós como um sonho sem substância ou uma forma etérea de fantasmas, não merecendo nossa atenção; ou, ao contrário, se é ainda outra coisa, algo fora dela, e então o que é ? ${ }^{4}$

Tal como nos indica a citação acima, os problemas levantados até aqui (sobre o conhecimento da essência dos fenômenos) referem-se à possibilidade de o mundo ser mais do que aquilo que é dado na representação do sujeito e à de se apreender o outro da representação como fundamento objetivo do mundo. Ao invés de simplesmente apontar no universo fenomênico sua essência e aparência, a solução schopenhaueriana será a de examinar a duplicidade de um objeto especial, dado de maneira mediata e imediata, a saber: o próprio corpo em ação.

Para Schopenhauer, se há uma essência verdadeira e indestrutível do mundo, ela tem de ser buscada, tal como dissemos acima, no agir dos corpos que o constituem. $\mathrm{O}$ único ponto que pode unir os atos corporais e o conhecimento é o próprio corpo do sujeito que conhece. A intersecção entre o que está fora da representação e o que é construído no conhecimento formal se dá na relação que cada um tem com o seu corpo. O problema da realidade objetiva do mundo pode assim ser posto sob estes termos: como é possível chegar à essência universal e verdadeira de todas as coisas partindo de um âmbito tão

3. Cf. Idem, $\S 4$, p. 42 .

4. Idem, § 17, p. 156 
próprio e subjetivo a cada indivíduo - o do próprio corpo? A experiência subjetiva que cada um tem com o seu corpo permitiria a decifração do enigma do mundo e revelaria a sua verdade. Mas se tomarmos o corpo como único fenômeno da vontade, não estaríamos reduzindo o restante do mundo a uma mera fantasmagoria? Perguntamo-nos ainda: como garantir que o corpo não seja um objeto privilegiado, diferente dos demais? O que permite estender a vontade, como essência verdadeira e indestrutível do corpo (Leib), ao mundo corpóreo (Weltkörper) e atribuir também a este a mesma verdade e indestrutibilidade daquele?

\section{O corpo como vontade e representação}

O conhecimento do corpo se caracteriza por um duplo aspecto: ou é dado mediatamente como representação, ou imediatamente (isto é, sem a mediação do entendimento), como vontade. No que concerne ao primeiro aspecto, o corpo é um objeto como outro qualquer, subordinado ao princípio de razão. Seus atos e movimentos são tomados como modificações que ocorrem em qualquer objeto do sentido externo, isto é, como efeito que se liga a uma causa. O corpo assim entendido está submetido às formas da representação. Por outro lado, como afirma Schopenhauer no $\S 18$ de O Mundo como vontade e representação, o conhecimento não se dá numa "cabeça de anjo alada, sem corpo", e não pode ser separado deste. Ao lado do exercício do entendimento no conhecimento do fenômeno (que o condiciona às formas da representação), o corpo pode ser conhecido como objeto ${ }^{5}$ imediato (unmittelbar $\left.{ }^{6}\right)$, sem a interposição das formas do entendimento, identificando-se assim com a vontade, isto é, com a essência íntima que fundamenta a existência e o conhecimento do corpo. É nesse sentido que o corpo permite conhecer algo essencialmente diferente da representação, cujas formas e leis lhe são completamente estranhas.

5. Schopenhauer nos adverte que não toma a palavra "objeto" em sua acepção estrita, isto é, como uma representação que existe apenas por e para o entendimento (Cf. Idem, $§ 6$, p.52) e, com isso, possibilita o emprego do termo "objeto" para casos em que ele se refere à vontade.

6. Unmittelbar pode também ser traduzido por incomunicável, inaudito. Nesse sentido, é apenas por intermédio do entendimento que a tal objeto pode ser atribuído um nome e tornar-se comunicável. 
A essência dos fenômenos somente pode ser conhecida nos atos corporais ${ }^{7}$.

O corpo, considerado como vontade, não pode estar condicionado à relação de causa e efeito, isto é, ser tomado como o efeito de uma causa anterior. Todo ato verdadeiro (wabre Akt) da vontade é ação do corpo (Aktion des Leibes) e não há entre eles relação de sucessão ${ }^{8}$. Visto que a vontade manifesta-se no ato corporal, a verdade deste é a verdade daquela. As quatro classes do princípio de razão oferecem apenas relações externas ao ser íntimo das representações. Jamais se atingirá o interior das próprias coisa a partir do que é externo à sua essência9 ${ }^{9}$. A busca da essência das coisas a partir daquilo que lhe é externo oferece, segundo Schopenhauer, apenas imagens e nomes (Bilder und Namen) que nada revelam sobre o seu verdadeiro significado.

Para o filósofo, esse foi o erro cometido por todos os pensadores que o precederam: estes submeteram a vontade a leis e princípios que regem as representações e acabaram por criar um hiato entre a experiência e os resultados de seus pensamentos. A razão desse equívoco estaria na exclusão do conhecimento imediato de seus sistemas de pensamento, por duas razões: ou porque se subtrai da base desses sistemas a experiência imediata que se tem com o corpo ou porque essa experiência é submetida às condições formais dadas pelo intelecto. Em ambos os casos, os filósofos se ocuparam de meras relações formais entre as representações e o conhecimento não apreende nada mais do que uma imagem sem conteúdo. Falta aos sistemas desses pensadores a referência à realidade objetiva do mundo.

Ao contrário dos anteriores, o caminho proposto por Schopenhauer para o conhecimento da essência verdadeira e indestrutível de todas as coisas é dar positividade à metafísica desconstruída por Kant. Tal como nos mostra Cacciola em Schopenbauer e a questão do dogmatis$\mathrm{mo}^{10}$, a fim de não ferir as proibições instituídas pela crítica kantiana, Schopenhauer vê no corpo a possibilidade de erguer uma nova metafísica, que se remete em primeiro lugar à percepção interna da vonta-

7. Desse conhecimento deve-se abstrair o tempo, forma do sentido interno e véu intransponível da aparência.

8. Cf. Idem, § 18 .

9. Idem, § 17, p. 156.

10. CACCIOLA, M. L M. O. Schopenhauer e a questão do dogmatismo. São Paulo: Edusp, 1994, p. 35 et seq. 
de em cada ser humano. A metafísica de Schopenhauer não recorre a qualquer princípio transcendente para explicar a relação entre sujeito e objeto que fizesse do conhecimento uma mera abstração sem conteúdo. Fundamentar seu sistema sob tal base levaria certamente o filósofo ao mesmo erro cometido pelos seus antecessores, a saber: transportar o princípio de razão que afeta as representações abstratas para o fundamento das representações. Em Fragmentos para a bistória da filosofia ${ }^{11}$, Schopenhauer escreve que a falha de seus antecessores, a saber: tomar como ponto de partida de seus sistemas uma essência inteligente do sujeito, subordinada às leis que regem a representação, impediu a consideração do seguinte problema: ao proporem um conhecimento do sujeito mediado por conceitos, esqueceram-se de que sujeito e objeto são coisas diferentes e que o sujeito que conhece jamais pode tornar-se objeto de conhecimento ${ }^{12}$.

Toda representação pressupõe a separação entre sujeito e objeto. Como vimos, a ela se aplicam os conceitos de espaço, tempo e causalidade, que nada valem para além do campo da representação. E uma vez que sujeito e objeto do conhecimento devem ser distintos, para que o segundo ganhe representação, o primeiro deve estar fora do campo fenomênico, isto é, não estar condicionado às formas da representação. Se Schopenhauer pretende conhecer a essência do mundo, isto é, torná-la objeto para um sujeito, encontra, como já foi dito, no corpo a possibilidade de união entre a parte que conhece e a que é conhecida. Ao contrário dos objetos do sentido externo, que são dados apenas como representação (isto é, de modo mediato), o corpo permite conhecer imediatamente (isto é, sem a aplicação do princípio de razão - Satz vom Grunde) o infundado ou sem fundamento (Grundlos), que vai além das formas da representação. É a esse fundo do conhecimento destituído de razão que Schopenhauer dará o nome de vontade.

Se todo conhecimento pressupõe a separação entre sujeito e objeto, também a consciência de si, na medida em que é conhecimento, deve ser pensada segundo essa divisão (mas, ao contrário dos objetos do sentido externo, de modo imediato). Unem-se, assim, sujeito e objeto e, se aqui ainda falamos em um sujeito, não é senão em sua

11. SCHOPENHAUER, A. Fragmentos para a bistória da filosofia. Tradução de Maria Lúcia Cacciola. São Paulo: Iluminuras, 2003. p. 58 et seq.

12. Cf. CACCIOLA, M. L. M. O. Schopenhauer e a questão do dogmatismo, p. 120. 
junção com o objeto do conhecimento. A vontade se dá para o sujeito somente na identidade entre a parte que conhece e a que é conhecida. A essa unidade, Schopenhauer denomina "indivíduo" ou "eu". Segundo Ciamarra, a crítica schopenhaueriana da concepção tradicional de intelecto converte o en em um milagre metafisicamente descrito "como o ponto de fusão do sujeito do conhecimento e sujeito da vontade, e intuitivamente como o ponto de indiferença entre a afecção do corpo e a atividade do intelecto"13. O indivíduo é o lugar privilegiado de contato entre o elemento essencial (primitivo) e o secundário, onde ambos são dados numa mesma coisa. Escreve Schopenhauer em sua obra principal:

Ao sujeito do conhecimento, que por sua identidade com o corpo apresenta-se como indivíduo, é dado esse corpo de dois modos totalmente diferentes: um, como representação na intuição intelectual, como objeto dentre objetos e submetido a suas leis; e, ao mesmo tempo, de um modo totalmente outro, a saber: como o conhecimento imediato de cada um, que designa a palavra vontade. ${ }^{14}$

$\mathrm{Na}$ consciência de si, o sujeito se torna conhecido para si mesmo; ele tem assim de estar dividido em uma parte que conhece e outra que é conhecida. A primeira, Schopenhauer denomina sujeito do conhecimento; a segunda, sujeito do querer. O sujeito do conhecimento, como a parte que conhece, é desconhecido para si mesmo, pois se se tornasse coisa conhecida, deixaria de ser sujeito que conhece. A autoconsciência é definida pelo filósofo como um conhecimento relativo: nele, o que é conhecido é o querer, manifesto no corpo em ação, isto é, em seus apetites e impulsos que são dados como bem-estar e mal-estar, ou ainda, prazer e desprazer (o primeiro como satisfação da vontade, o segundo como impedimento para sua satisfação). Esses apetites e impulsos dão ao sujeito do conhecimento a ocasião de conhecer o sujeito do querer como um ímpeto sem consciência, enraizado no corpo. O eu é o ponto de contato e indiferenciação entre ambos os lados do sujeito, mediante o qual o sujeito se conhece como um impulso que quer cegamente, sem finalidade. Essa identidade é definida por Schopenhauer como um mistério, pois encontra nessa coincidência entre sujeito do querer e do conhecer o limite da própria consciência.

13. CIAMARRA, L. P. L'antropologia di Schopenbaner. Loffredo: Napoli, 1996, p. 69.

14. SCHOPENHAUER, A. Die Welt als Wille und Vorstellung, § 18, p. 157 
A vontade é definida como o elemento originário em relação à parte que conhece. E uma vez que ela é conhecida nas ações do corpo, toda sua atividade intelectual deve estar fundamentada sobre a atividade do querer, não consciente. A vontade é assim o fundamento da consciência de si e do restante das representações produzidas pelo intelecto, estando todo o conhecimento arraigado nela. É por esse motivo que o corpo é posto na filosofia schopenhaueriana não apenas como a chave para o conhecimento de si, mas também como a solução para o enigma do mundo. Uma vez que o sujeito do conhecer enraíza-se no sujeito do querer, toda atividade intelectual deve ser também ato corporal e ocorrer em um lugar especial, a saber, no cérebro. Para que o corpo possa ser considerado de modo duplo, é preciso que o próprio entendimento ganhe uma dimensão fisiológica: além de estabelecer a intuição como intelectual, as representações criadas pelo entendimento devem ser o resultado de uma atividade do próprio corpo (do cérebro), e esta, por sua vez, inconsciente em sua essência.

Surge, assim, o seguinte problema: se, por um lado, todo o mundo que nos aparece (do qual o cérebro, por sua natureza corporal, não pode ser excluído) é mera representação do sujeito; por outro lado, o conhecimento do mundo fenomênico é um produto da atividade cerebral. O pensamento de Schopenhauer parece cair em uma contradição, pois, tal como acabamos de expressar, o cérebro teria sua fonte na representação e a representação sua fonte no cérebro. Como as representações podem ter sua origem na própria representação? Esse problema, classicamente conhecido como "paradoxo de Zeller", aponta para um impasse no interior da teoria da representação schopenhaueriana, ou ainda, tal como denomina o filósofo, para uma antionomina da faculdade de conhecer ${ }^{15}$. A intenção de Schopenhauer não é a de eliminar o paradoxo, mas a de ressaltar a sua necessidade no campo fenomênico e oferecer uma saída para ele fora do campo da representação. Para isso, adota o mesmo procedimento de Kant na resolução das antinomias da razão, a saber, a distinção entre fenômeno e coisa-em-si. Ao se levar em conta o mundo fenomênico, o sujeito do conhecimento é sua causa e seu resultado e o paradoxo torna-se insolúvel; ao tomarmos o mundo como vontade, fora do espaço, tempo e causalidade, desaparecem a particularidade, a sucessão e a diferença entre sujeito e objeto, pondo um fim à relação de causa e

15. SCHOPENHAUER, A. Die Welt als Wille und Vorstellung. § 7, p. 66. 
efeito que ocasionava o impasse à teoria representacional. A vontade, entendida como coisa-em-si, encontra-se fora dessa contradição radical e insolúvel do mundo fenomênico ${ }^{16}$.

Ora, e o que legitima estender as conclusões a que Schopenhauer chega a partir do corpo para o restante do mundo da representação? Não seria o próprio corpo um objeto privilegiado dentre os demais, e o restante do mundo fenomênico mera fantasmagoria, destituída de qualquer verdade?

\section{Da duplicidade do corpo à duplicidade do mundo}

A identidade do sujeito do querer com o sujeito que conhece permite descobrir a vontade como a essência verdadeira e indestrutível do homem. A subordinação do intelecto à atividade volitiva inconsciente não faz do homem um ser incapaz de atividade consciente. A ação mediada pelo conhecimento é o efeito que tem no motivo a sua causa. $\mathrm{O}$ motivo é para Schopenhauer a causalidade intermediada pelo conhecimento. A ausência deste tem por consequência a anulação do motivo.

As representações produzidas pela consciência de si estão subordinadas à quarta classe do princípio de razão suficiente, a saber, a do agir, caracterizada pela lei da motivação. A identidade do sujeito do querer com o do conhecimento dada ao sentido interno permite que Schopenhauer passe das representações da consciência de si às da consciência externa e estabeleça uma analogia entre o corpo e o mundo. Isso é feito com a remissão da quarta classe à primeira, da seguinte maneira: o sujeito do querer (apreendido pelo sentido interno e submetido à quarta classe) é objeto do conhecimento e, enquanto tal, tem de estar subordinado também à primeira classe que rege as representações intuitivas em geral e que na apreensão dos objetos externos aparece como o encadeamento necessário entre causa e efeito. A lei da motivação é um desdobramento da lei da causalidade: causa e efeito se traduzem nela por motivo e ação. A diferença entre causa e motivo está no fato do motivo ser a causa da ação mediada pelo conbecimento ${ }^{17}$. Ver na motivação o correlato subjetivo da lei da causalidade que rege o restante do mundo fenomênico é o que permite passar da quarta

16. Cf. CACCIOLA, M. L. M. O. Schopenhauer e a questão do dogmatismo, p. 77 et seq.

17. Devemos notar que, por ser mediado pelo conhecimento, o motivo é causa secundária da ação. 
classe das representações para a primeira, ou ainda, do que nos é dado como vontade e representação (o corpo) para o que nos é dado apenas como representação (o restante do mundo) ${ }^{18}$. Com isso, estende-se a verdade do conhecimento dado pelo sentido interno para as intuições dos objetos externos e conclui-se que do mesmo modo como o corpo pode ser dado como vontade e representação, também o mundo deve assim ser concebido. Nas palavras de Schopenhauer:

[...] julgamos [todos os objetos] justamente por analogia com aquele corpo [o nosso] e, por isso, admitimos que eles, por um lado, são representação e parecidos nisso como ele; por outro lado, se se coloca de lado sua existência como representação do sujeito, o resto que permanece tem de ser, por sua essência íntima, o mesmo que o que chamamos em nós vontade. ${ }^{19}$

O mesmo significado atribuído ao meu corpo (Leib) e às suas ações pode ser conferido, por analogia, ao mundo corpóreo (Körperwelt). $\mathrm{O}$ fundamento de todo o mundo objetivo encontra-se em um outro campo, essencialmente diferente daquele do fenômeno, isto é, na vontade. Neles mesmos, espaço, tempo e causalidade apenas podem nos dar formas vazias que encontram o seu conteúdo para além deles mesmos. Se o próprio mundo não estivesse enraizado na vontade, toda notícia que teríamos dele seria uma mera fantasmagoria.

Quando Schopenhauer afirma que o motivo é a causa mediada pelo conhecimento, ele não se refere apenas ao homem, mas também aos animais, capazes de conhecimento intuitivo ${ }^{20}$. Nos demais seres, incapazes de conhecer, a causa da atividade e do movimento deve se encontrar em algo correlato ao motivo. Das diferentes maneiras como a lei da causalidade se manifesta na natureza, Schopenhauer distingue os diferentes reinos: animal, vegetal e inorgânico ${ }^{21}$. Vale notar que a classificação dos seres não é feita por suas propriedades

18. Buscamos na Dissertação de 1813 a explicação para a analogia entre micro e macrocosmo. Essa posição será reforçada na $2^{a}$ edição d'O Mundo (Cf. Complemento XXIII - Sobre a objetivação da vontade na natureza inanimada).

19. SCHOPENHAUER, A. Die Welt als Wille und Vorstellung, § 19, p. 164.

20. O homem é capaz de conhecer não apenas intuitivamente (como os animais), mas também abstratamente.

21. Idem, § 23. 
anatômicas, mas pelos distintos modos de expressão da lei da causalidade. Esta se manifesta em três tipos, a saber: o motivo (na animalidade), a excitação (no vegetal) e a causa (no inorgânico); esses gêneros enumerados por Schopenhauer são igualmente objetividades de uma mesma vontade.

O fundamento do ato do corpo é estendido para todas as atividades externas ao sujeito. Tal como afirma Brandão ${ }^{22}$ os conceitos de movimento e atividade são de fundamental importância para a compreensão da passagem da quarta classe à primeira (ou ainda, do corpo ao mundo): motivo, excitação e causa determinam o caráter do que é posto em movimento ou em ação. A vontade, tomada como coisa em si, como essência do fenômeno, está fora das formas do princípio de razão e, consequentemente, da multiplicidade e da sucessão do mundo da representação. A unidade essencial e original da vontade a que se refere Schopenhauer não deve ser entendida como a de um objeto, cuja unidade esteja apenas na oposição à pluralidade ou na composição de um conceito abstrato, mas como a unidade de algo que está fora do espaço e do tempo, formas que inscrevem a pluralidade e a sucessão no seio da representação. Por outro lado, enquanto fenômeno condicionado ao princípio de razão, a vontade engendra todo movimento e toda multiplicidade, os quais dependem do caráter do corpo em que se objetiva. Schopenhauer descreve os graus de seres do mais baixo ao mais elevado: na natureza inorgânica, a causa é o que move as forças físicas e químicas e a vontade se apresenta como um ímpeto cego e sem conhecimento; no mundo vegetal, a excitação move os seres não dirigidos pelo conhecimento (as atividades cegas das plantas e do inconsciente vegetativo animal); apenas o animal é movido por motivos, pois pertence ao caráter da animalidade as representações intermediadas pelo conhecimento. $\mathrm{O}$ conhecimento se manifesta apenas no reino animal, como intuitivo (que tem sua fonte no entendimento e se manifesta no homem e nos animais) e abstrato (dado pela razão e engendrado apenas no homem). No homem, que ocupa o nível mais elevado de objetivação da vontade, as representações abstratas aperfeiçoam as intuitivas. Novamente podemos frisar o caráter contraditório da teoria da representação de Schopenhauer: o mundo, com seus diferentes reinos, depende da sucessão e da multiplicidade

22. BRANDÃO, E. A concepção de matéria na obra de Schopenbauer. São Paulo: Humanitas, 2008, p. 226 et seq. 
para poder existir ${ }_{i}$ contudo, sucessão e multiplicidade apenas podem existir mediante um sujeito que conhece e que ocupa a escala mais elevada dos seres. Se as relações de causalidade e de anterioridade devem pressupor um sujeito do conhecimento, como o conhecimento pode ser o produto mais elevado de graus inferiores que o precedem? A solução schopenhaueriana deve distinguir o mundo entendido como fenomênico e o entendido como coisa em si, e ver na vontade a essência única de todos os seres, subtraída das formas da representação. Desse modo, o filósofo pode afirmar que a mesma força que age em uma pedra que cai é, em sua essência e fora da representação, a mesma que age no crescimento das plantas ou nas ações humanas. A remissão da quarta classe à primeira reúne o movimento em todos os reinos sob a lei da causalidade, não sendo possível conceber fenômeno algum como um efeito sem uma causa.

No § 23 do Mundo, Schopenhauer afirma que a distância entre o reino inorgânico e orgânico é uma mera aparência (Schein) que não se encontra na essência das próprias coisas, mas antes, na relação (Verbältnis) que "a vontade como coisa em si tem com o seu fenômeno, isto é, [que] o mundo como vontade tem com o mundo como representação" ${ }^{\prime 23}$. O autor propõe dois tipos de composição entre esses elementos: uma mensurável, outra incomensurável. Ele escreve:

Além disso, na causa genuína, o efeito cresce exatamente na mesma proporção que a causa, que é a mesma da reação; assim, se o modo de ação é conhecido, o grau do efeito é medido e calculado pelo grau de intensidade da causa, e também o inverso. Essas causas propriamente ditas agem em todos os fenômenos da mecânica, da química etc., sucintamente: em todas as modificações dos corpos inorgânicos. Ao contrário, chamo excitação aquela causa que não sofre nenhuma reação que corresponda à sua própria ação, e cuja intensidade não se move de modo algum paralelamente ao grau de intensidade do efeito, que não pode, por consequência, tornar-se medida. [...] todo efeito sobre um corpo organizado é desse tipo. ${ }^{24}$

Nos fenômenos mecânicos, elétricos e químicos do mundo inorgânico, a intensidade da causa é proporcional ao seu efeito e ambas podem ser identificadas. Há assim uma relação direta, neces-

23. SCHOPENHAUER, A. Die Welt als Wille und Vorstellung, § 23, p. 181-82

24. Idem, § 23, p. 177. 
sária e evidente entre as forças de ação e reação que estão em jogo nos corpos inorgânicos. Por outro lado, o caráter dos corpos organizados anula a lei de igualdade entre ação e reação: não é mais possível verificar no vegetal e no animal uma proporção exata entre a excitação e o seu efeito. A quantidade de força em ambos os lados já não pode mais ser medida e posta em equilíbrio. A igualdade entre ação e reação no mundo inorgânico nos permite conhecê-lo segundo leis gerais (allgemeinen Gesetzen) invariáveis: não importa o número de vezes que uma pedra seja solta no espaço, a reação será sempre a mesma (a queda). No reino orgânico, ao contrário, a possibilidade de determinar a ação depende da potência de individualidade do ser: quanto maior for essa potência, maior é o grau de indeterminação de sua reação frente a uma causa. Para os corpos organizados, é perfeitamente possível que um pequeno aumento da excitação produza um efeito de grandes proporções. Dentre os seres, o homem é aquele cuja individualidade aparece em sua maior potência. Isso é o que permite a cada homem ter o seu próprio caráter. Com isso, o motivo age diferentemente em cada um, impossibilitando dar às ações humanas o mesmo nível de previsibilidade dos fenômenos inorgânicos. Mediado pelo conhecimento (não apenas intuitivo, como nos animais, mas também abstrato, dado pela razão), o homem leva em conta inúmeras circunstâncias em seu agir e a reação a um motivo somente pode ser conhecida quando efetivamente realizada. Antes de sua efetivação, a ação é pura abstração, dada pelo intelecto, e nada tem a ver com a relação (Verbältnis) entre a coisa em si e o seu fenômeno ${ }^{25}$.

Devemos notar que mesmo mediado por inúmeras circunstâncias no conhecimento, a relação entre motivo e ação é determinada pelo caráter do indivíduo. A correspondência entre a quarta e a primeira classe de representações dá às ações humanas a mesma necessidade que aquela inscrita na natureza inorgânica. Schopenhauer não deixa de frisar a aparência do livre arbítrio e do contraste entre o agir humano e a atividade ou movimento de todos os outros seres. Perguntamo-nos, então: haveria lugar para a liberdade na filosofia de Schopenhauer ou esta estaria relegada à mera ilusão?

25. Cf. BRANDÃO, A concepção de matéria na obra de Schopenhauer. 


\section{Metafísica da natureza e metafísica dos costumes}

Ao percorrermos a natureza em seus diferentes graus de objetivação da vontade, quanto mais nos distanciamos do homem, menor é o traço de particularidade do caráter. A igualdade entre ação e reação que nos permite atribuir leis gerais aos fenômenos físicos e químicos está ligada ao fato de não haver qualquer individualidade na natureza inorgânica ${ }^{26}$. Isso não significa que os corpos, para além dos do homem, não tenham um caráter, mas apenas que este não se apresenta neles de modo individualizado, e sim como caráter da espécie. Como manifestação imediata da vontade, a atividade ou movimento é a essência verdadeira e indestrutível do ser; revela, dessa maneira, o caráter do que está posto em ação. E já que apenas os homens têm um caráter individual, para todo o restante da natureza o caráter será atribuído não ao ser em particular - já que nela não há individualidade - mas aos graus de objetivação da vontade. A eletricidade e a gravidade especificam o caráter do corpo (Körper) em que se manifestam ${ }_{i}$ correlatas a elas, as ações humanas revelam o caráter da vontade objetivada naquele corpo (Leib) que age.

O caráter não necessita da mediação do conhecimento para existir, pois pode revelar-se nos diferentes graus de manifestação da vontade, ou ainda, podemos dizer, na ideia que neles se manifesta. Caráter ou ideia designa, segundo Schopenhauer, a "objetidade" da vontade, isto é, o fenômeno primeiro, mais imediato da vontade. As ideias contêm as inúmeras possibilidades de manifestação da essência una e indivisa dos seres, como formas eternas, estranhas à multiplicidade e à sucessão das representações postas no espaço e no tempo. As espécies tratadas por Schopenhauer são também ideias e designam os estágios de objetivação da vontade. O conhecimento dos distintos graus de manifestação da vontade ocorre apenas no homem, momento privilegiado em que a vontade, colocada sob as formas intelectuais, conhece a si mesma na pluralidade. As ideias dispõem toda a natureza em níveis que vão do mais baixo ao mais alto. No grau mais inferior encontramos a matéria inorgânica, que manifesta o seu caráter como forças físicas e químicas (tal como a eletricidade e a gravidade enumeradas acima). As plantas e os animais corresponderiam a graus mais elevados de manifestação da vontade, irredutíveis às forças inorgânicas (encontradas na lei de igual-

26. Cf. SCHOPENHAUER, A. Die Welt als Wille und Vorstellung, § 26, p. 198 
dade entre ação e reação). No mundo orgânico, as ideias das quais decorre o caráter dos corpos inorgânicos não desaparecem, elas se encontram apenas subjugadas pelas ideias de maior perfeição, que lutam para tomar posse da matéria. O caráter dos corpos orgânicos é o resultado do triunfo de formas superiores sobre as inferiores.

Toda multiplicidade refere-se apenas ao que é determinado pelo intelecto e existe apenas no entendimento. A individuação é, tal como afirma Schopenhauer, uma mera aparência e está condicionada às formas do entendimento que, por sua vez, são frutos de uma atividade do cérebro. A diferença entre os indivíduos existe apenas na representação de um sujeito; cada indivíduo, como união entre sujeito do querer e do conhecer, coloca-se em dois campos diferentes: o da representação, que é mera aparição da ideia no espaço e no tempo, e o da vontade, que compartilha a verdade e unidade do mundo. O conhecimento dá assim a cada homem a ocasião de manifestar o querer de modo particularizado. Ao contrário dos demais seres, cuja multiplicidade resulta do princípio de individuação, no homem a vontade ganha uma individualidade, contudo, não dependente de tal princípio. Essa particularização da vontade dá a cada homem um caráter que se manifesta segundo as formas da representação e também fora delas: na medida em que está fora do tempo, livre de toda multiplicidade e sucessão, é denominado inteligível; o caráter empírico, por sua vez, é a manifestação do inteligível sob as determinações da lei da motivação (isto é, da sucessão de causa e efeito intermediada pelo conhecimento). Subordinado às formas da representação, o caráter empírico, tomado em si mesmo, é meramente ilusório e encontra o seu significado no inteligível.

Para Schopenhauer, o lugar da liberdade e da moralidade não pode ser o da multiplicidade. Por outro lado, apenas o ato do indivíduo pode ser a fonte da ordenação moral do mundo. No que diz respeito à moralidade, cada homem tem um caráter inteligível, que, subtraído da sucessão temporal, está fora da relação de causa e efeito. Ele não pode ser direcionado por nenhuma causa externa e, nesse sentido, é imutável. O caráter empírico, como manifestação do caráter inteligível segundo a lei da motivação, deve ser visto da mesma maneira que o restante dos fenômenos naturais, a saber, tendo uma causa (o motivo) que determina uma reação (o agir). Não há, desse modo, liberdade no campo da individualidade. Tudo ocorre, tal como na natureza, necessariamente: do motivo tem-se a ação. A remissão da motivação à causalidade permite a Schopenhauer falar de uma necessidade moral 
e reportá-la a uma necessidade física encontrada na sequência causa-efeito: dado o motivo, o homem ou o animal é obrigado agir de acordo com o seu caráter (que é inato e invariável). Mesmo que de difícil previsão, há nas ações o mesmo determinismo que encontramos na queda de uma pedra.

O conhecimento de um fundo único por trás do indivíduo ou dos graus de objetivação dos seres na natureza é a tarefa da metafísica (entendida como metafísica da natureza ou dos costumes), é apenas a partir desse campo que a vontade pode ser apreendida como a verdadeira e indestrutível essência de todos os seres. Mas qual seria o lugar da liberdade na filosofia de Schopenhauer se o caráter empírico é a expressão fenomênica do inteligível e este, subtraído de toda forma que determina a multiplicidade, eterno e imutável? É da metafísica (isto é, o conhecimento da essência única de todos os fenômenos sem recorrer a algo que transcenda o mundo) que Schopenhauer deduz a sua ética como a supressão da atividade da vontade na suspensão da atividade do próprio corpo, que é a sua objetivação. O conhecimento da essência do conjunto de todas as coisas, possibilitada pelo conhecimento da essência do próprio corpo, leva o homem ao mais alto grau de consciência, a saber: a negação da vontade na supressão de seu próprio caráter. Esse é o único momento em que a liberdade da vontade (entendida como coisa em si) apresenta-se no mundo fenomênico. A liberdade estaria, assim, no ato individual da vontade negar a si mesma. A negação da vontade em sua individualidade não deve ser entendida como a morte efetiva do indivíduo, mas como uma "morte simbólica" ${ }^{\prime 27}$, isto é, como o rompimento da cadeia dos fenômenos da vontade, que se manifesta como um conflito incessante da vontade com ela mesma, num sofrimento contínuo e sem finalidade.

Para concluir, colocamos a seguinte questão: como ficaria a relação entre verdade e ilusão diante da negação da vontade? Suprimiríamos a ilusão para alcançar a pura verdade? Schopenhauer afirma no início dos livros I e II de sua obra principal que o mundo é sua vontade e sua representação, ambos os lados estão em relação um para com o outro e não podem ser vistos como pontos absolutos de sua filosofia. O mesmo poderia ser afirmado das concepções de verdade e ilusão: assim como a vontade só pode ser dita coisa em si em relação ao fe-

27. CACCIOLA, M. L. M. O. A vontade e a pulsão em Schopenhauer. In: As pulsões. São Paulo: Escuta/Educ, 1995, pp. 61-62. 
nômeno, do mesmo modo a essência do mundo encontra a sua verdadeira significação apenas em relação à sua aparência. Verdade e ilusão são duas faces de uma mesma coisa: o mundo como vontade e como representação. Não se poderia, assim, suprimir um dos lados, sem que se elimine, ao mesmo tempo, o outro; fato que é valido tanto para a verdade em relação à sua aparência ou ilusão quanto para vontade em relação à representação. A negação total da vontade seria, pois, imediatamente a negação de todo o mundo da representação. Negar um dos polos é destruir a duplicidade da qual eles dependem.

O conhecimento desta duplicidade do mundo, alcançado pela compreensão da duplicidade do corpo, e a apreensão da relação que a ordem metafísica (o outro lado do fenômeno na natureza e na moralidade) tem para a compreensão da ordem física do mundo, não se dão, na filosofia schopenhaueriana, nos moldes de um sistema fechado e sem lacunas, que conferiria ao sujeito o poder de conhecer uma verdade absoluta. Tal como pudemos expor no presente texto, corpo e mundo são entendidos como realidade e como construto de fantasia, e colocam para o pensamento contemporâneo um problema sobre o qual autores como Freud, Marx e Nietzsche se debruçarão, a saber: o da própria limitação interpretativa do homem.

\section{Referências bibliográficas:}

BRANDÃO, E. A concepção de matéria na obra de Schopenhauer. São Paulo: Humanitas, 2008.

CACCIOLA, M. L. M. O. A Crítica da Razão no Pensamento de Schopenbauer, 1981. 125p. Dissertação (Mestrado em Filosofia) - Faculdade de Filosofia, Letras e Ciências Humanas, Universidade de São Paulo, São Paulo, 1981.

Schopenhaner e a questão do dogmatismo. São Paulo: Edusp, 1994.

A vontade e a pulsão em Schopenhauer. In: As pulsões. São Paulo: Escuta/Educ, 1995.

CIAMARRA, L. P. L'antropologia di Schopenhaner. Loffredo: Napoli, 1996.

HARTMANN, N. A filosofia do idealismo alemão. Lisboa: Calouste Gulbenkian, 1976.

JANET, P. Schopenhauer et la physiologie française. Cabanis et Bichat. In : Revue des deux mondes. Tome. 39. Paris: Bureau de la Reveu des deux mondes. 1er Mai 1880.

LEFRANC, J. Schopenbaner lecteur de Cabanis. Revue de métaphysidue et de morale. LVIII, 1983, pp. 549-57. 
PICHOT, A. Histoire de la notion de vie. Paris : Gallimard, 1993.

RAMOS, F. C. Tragédia e redenção: o significado moral da existência na filosofia de Schopenhauer, 2003, 170 p. Dissertação (Mestrado em Filosofia) - Faculdade de Filosofia, Letras e Ciências Humanas da Universidade de São Paulo, 2003.

SCHOPENHAUER, A. Die Welt als Wille und Vorstellung. In: Sämtliche Werke. Vol. I. Ed. Wolfgang Frhr. von Löhneysen, Frankfurt am Main : Suhrkamp, 1986.

Die Welt als Wille und Vorstellung. In: Sämtliche Werke. Vol. II. Ed. Wolfgang Frhr. von Löhneysen, Frankfurt am Main : Suhrkamp, 1986.

Über den Willen in der Natur. In: Sämtliche Werke, vol. III. Ed. Wolfgang Frhr. von Löhneysen, Frankfurt am Main : Suhrkamp, 1986. De la volonté dans la nature. Paris : Quadrige / PUF, 1996.

Sobre o fundamento da moral. Trad. Maria Lúcia Cacciola. São Paulo : Martins Fontes, 2001.

Fragmentos para a bistória da filosofia. Trad. Maria Lúcia Cacciola. São Paulo: Iluminuras, 2003. 2005.

Parerga \& paralipomena: Petits écrits philosophiques. Paris : Coda, O mundo como Vontade e Representação. Trad. Jair Barboza. São Paulo: Ed. UNESP, 2005. 


\title{
Retorno à querela do Trieb: por uma tradução freudiana
}

\author{
Ivan Ramos Estêvão \\ Professor da Escola de Artes, Ciências e Humanidades da USP. \\ Psicanalista, Doutor em Psicologia Clínica pela USP.
}

Resumo: 0 artigo tem como intuito retomar 0 debate sobre a tradução dos textos de Freud, focando-se no conceito de Trieb, um dos mais importantes da psicanálise freudiana e também 0 de mais difícil tradução. Nossa tese é que, ao contrário do que os tradutores costumam apontar, a escolha entre os dois termos mais populares - instinto ou pulsão - não se dá por fatores técnicos, mas principalmente por motivos políticos. Optamos por abordar o tema a partir de três pontos da obra freudiana, a saber, a teoria do desejo e da responsabilidade, 0 debate entre sua posição natureza versus cultura e sobre a hereditariedade.

Palavras-chave: Psicanálise, Freud, tradução, pulsão, instinto, desejo, Trieb.
Abstract: The article has the intention go back to the debate about the translation of Freud's writings, focusing on the concept of Trieb, one of the most important in Freudian psychoanalysis and also the most difficult to translate. Our thesis is that unlike the translators usually claim, the choice between the two Portuguese most popular terms - instinto or pulsão - is not due to technical factors but primarily to political ones. We choose to approach this matter from three points of Freudian work, that is, the theory of desire and responsibility, the debate between the naturalist and the culture position and about the heredity theory.

Keywords: Psychoanalysis, Freud, translation, drive, instinct, desire, Trieb.

\section{1 - Introdução}

Em 2009 completaram-se 70 anos da morte de Freud. Isso significa que os direitos de publicação de seus textos caíram em domínio público. Trata-se de um fato a comemorar, principalmente por conta das já bem conhecidas deficiências da tradução Standard Brasileira das Obras Completas de Freud, publicada pela editora Imago, até então detentora dos direitos de publicação de Freud. Esperava-se que, com isso, surgissem grandes traduções, melhores inclusive do que a nova tradução empreendida também pela Imago sob a coordenação de Luiz Hanns. 